\title{
To Ask Questions of the Universe: Confronting Habitus for Racial Equity with Descriptive Inquiry
}

\author{
Cara E. Furman ${ }^{1}$ (D) Cecelia E. Traugh ${ }^{2}$
}

Accepted: 4 January 2022 / Published online: 1 March 2022

(c) The Author(s), under exclusive licence to Springer Nature B.V. 2022

\begin{abstract}
This paper is premised on the understanding that racism is deeply and widely entrenched in our culture and the ethical claim that we operate within complex networks of habituated practices. Within this framework, we ask how do we disrupt these calcified, complex, and racist ways of being? Specifically, we explore how teachers are habituated into particular ways of seeing and acting. We argue generally that conscious cultivation can promote greater equity and specifically that changing teacher talk is a necessary part of this cultivation if racist norms are to be disrupted and replaced with more equitable ways of seeing in schools. In making this argument, we draw on a practice, Descriptive Inquiry, to cultivate more equitable talk and describe how it led to changes in four urban public schools.
\end{abstract}

Keywords Teacher education $\cdot$ Antiracism $\cdot$ Ethics

To ask questions of the universe, and then learn to live with those questions, is the way he achieves his own identity. But no society is really anxious to have that kind of person around. What societies really, ideally, want is a citizenry which will simply obey the rules of society. If a society succeeds in this, that society is about to perish. The obligation of anyone who thinks of himself as responsible is to examine society and try to change it and to fight it - at no matter what risk. This is the only hope society has. This is the only way societies change. -James Baldwin (1963)

I (Cara) am in a meeting with colleagues at a progressive elementary school committed to racial justice. We are discussing a child who is struggling in our school. I have just presented a detailed description of the child referred to as a Descriptive Review. I have written this review in my own time in preparation for this meeting. Unsolicited, I elected to do this because the child had become increasingly invisible in our school-noticed often through negative reactions to behavior. At stake in this meeting is whether or not we refer the child for additional services. With no identifiable disability, the label being debated is "emotionally disturbed." I am agitated during the meeting believing that affixing a child with such

Cara E. Furman

Cara.furman@maine.edu

1 Education Center Rm. 303, University of Maine at Farmington, 186 High Street, Farmington, ME 04938, USA

2 Bank Street Graduate School of Education, New York, NY, USA 
a phrase is damaging, inappropriate, and because the diagnosis is so vague, not helpful. It matters that the child is Black and the majority of the teachers in this conversation are White. It matters that Black children are disproportionately diagnosed with learning disabilities and labelled emotionally disturbed (Love, 2018). In the meeting, I am part of what I know statistically to be true and unjust. Trying to lodge my concern, I feel silenced when my colleagues offer a different perspective. Frustrated with my perceived inability to look out for my student, I start to cry and angrily leave the room. After school, the principal calls and we discuss the situation more. Ultimately and after additional conversation, my colleagues and I develop a plan for the child with their mother that feels more humane and caring.

In her searingly honest essay, Kathe Jervis (1996) reckons with the racism endemic in daily practices at a newly formed school. As a teacher and researcher, Jervis documents many incidents that illustrate the subtle scope of racism amidst a school committed to its undoing. The article poignantly comes to a head in the school's inability to support a Black child and their mistreatment of him. In placing her subsequent reflection alongside her initial documentation and her colleagues' read of situations, Jervis highlights how racism was largely invisible to white staff members even in incidents where the racial overtones seem obvious to Jervis in retrospect. A second element that stands out for our work is that a White male teacher and White female principal led the charges against the child and that, hearing these charges, other teachers were unable to defend the child, name the racism they saw, and counter their colleagues.

In choosing these scenarios, we highlight the daily way in which racism surrounds children and teachers in American schools and the challenges that occur as teachers try to a) recognize this racism b) confront it and c) do better by students. Our exploration is premised in the understanding that teachers are habituated into particular ways of seeing and acting and disruption, as James Baldwin (1965) notes, is rarely welcomed. We ask how might schools cultivate teachers who question, challenge, and work against the racist status quo in light of Baldwin's contention that, "no society is really anxious to have that kind of person around" who "thinks of himself as responsible" and, in doing so, "examine[s] society and $\operatorname{tr}[i e s]$ to change it and to fight it."

We find most schools are also not "really anxious" to have this questioning person around. Even schools that position themselves as on the forefront of change tend to replicate and reinforce the world as is (Shalaby 2017) and struggle to make space for conversation that challenges norms (Jervis 1996). We argue that for schools to change, teachers must interrogate the ways in which they perceive children and their daily practices - specifically investigating whether these actions are serving Black children and making changes when they are not (Love 2019).

As a mixed methods paper, we bring together qualitative study and philosophical exploration to mutually reinforce each other (Santoro 2015). We begin with an overview of what racism looks like in schools and then focus on how teacher talk perpetuates racist perceptions and actions. We go on to describe habits of mind identified as necessary for developing an antiracist ethos through talk. Finally, drawing together antiracist pedagogy and ethics, we showcase how Descriptive Inquiry supported antiracist work in schools. 


\section{Racism in Schools}

After describing the racism he grew up amidst, Ibram X. Kendi (2019) attests "this was not a problem specific to my school or my childhood--it's a problem that cuts from private to public schools and through time" (45). A steady and pervasive stream of racism is endemic to schools in the United States (Boutte \& Bryan 2019; Jones \& Hagopian 2020; Shalaby 2017; Love 2018). Racism manifests in many and varied actions including but not limited to violent physical and verbal attacks (Love 2019), the invisibility and hypervisibility of Black children who are punished more frequently and more aggressively (Ferguson 2001; Ife 2017; Kendi 2019; Lomboy et al. 2020; Richards et al. 2019, Walker et al. 2017), reduced likelihood for Black children of being identified as high achievers (Boutte \& Bryan 2019), and increased likelihood of being affixed with a learning disability (Connor 2017). This dehumanization is compounded by the privileging of White students and their experiences (DiAngelo 2018; Love 2019), dominance of Whiteness and White people in curriculum (Baines, Tisdale \& Long 2018; Picower 2021), and disregard of the home culture and interests of children of color as displayed in curriculum, assessment, and daily treatment (Paris \& Alim 2014; 2017). In fact, often injustice manifests as subtle inequity masked in claims of benevolence (Alexander 2012; Love 2018; Shalaby 2017). Further, while we focus on children's experience in schools, it is important to recognize that schools are often toxic for all Black people including teachers (Frank et al. 2021; Jones \& Hagopian 2020).

While some racism is more overt, the subtle instances are widespread, normalize mistreatment (Baldwin 1965; DiAngelo 2018), and are deeply toxic (Baines, Tisdale \& Long 2018; Love 2019). Often characterized as "microaggressions" we instead use Kendi's description of these daily and more subtle examples as "racist abuse" (47) to emphasize that these acts are cruel, damaging, and pervasive (Hartman 1997; Moten 2017). We have made this daily and more subtle abuse our focus as the racism of many teachers falls into this category (DiAngelo 2018; Picower 2021).

Teachers often have neither the community to challenge their own racist assumptions nor the mechanisms and skills to address the racism of their colleagues effectively (Jones \& Hagopian 2020; Jervis 1996). In contrast, our study centers on urban public schools with racially diverse student and teacher populations and stated commitments to inclusion, equity, and racial justice in which daily "racist abuse" both occurs and is actively countered. We argue that it is not the lack of racism that sets these schools and their staff apart but instead the collaborative commitment to antiracism on a school-wide level. Specifically, we explore how within these imperfect but racial-justice seeking schools, a particular practice, Descriptive Inquiry, helped develop a culture that disrupted and challenged racism as it emerged in the teachers' daily talk and actions.

In focusing on schools and the teachers within them, a few caveats. First, racism is upheld by a complex system that reaches into all areas of life (Alexander 2012; Kendi 2019; McGhee 2021; Wilkerson 2020). Dismantling racism requires many different approaches acting in conjunction with each other. For example, for Black children to experience equity, the systems that govern schools, housing, laws, and health care, all need significant reform (Coates 2017; McGhee 2021). Further, racism symbiotically lives in our culture, societal structures, and within individuals (DiAngelo 2018; Kendi 2019). Therefore, as Baldwin's opening quote suggests, combating inequality requires that we dually address the individual and the society.

That said, where school reform focused on teachers cannot fix the whole problem, most children spend significant time in schools. Therefore, changing teachers' quotidian conduct 
will benefit the people in these spaces (Boutte \& Bryan 2019; Jones \& Hagopian 2020; Love 2019). Teachers have the potential to disrupt racism and improve the daily experiences of the children in their care (Love 2019; Picower 2021).

Bettina Love (2019) queries, "How do we hold teachers accountable for injustices in their classrooms that they themselves have caused?" (122). In answer, we further narrow our scope to one facet of reform, how shifts in every day discourse can lead to antiracist practices (Picower 2021; Tatum 2017). Writing of protest and social change, Eddie Glaude (2008) argues that effective actions speak to a time and place. Sit-ins and marches were particularly well-suited to protest segregation because the perpetuation of that injustice centered on oppressively restricting movement. Physically occupying and taking over spaces in protest spoke to the moment. In schools, teachers both pass on and challenge assumptions with talk (Frank 2018; Leafgren 2018). Therefore, as teacher talk serves as a key mechanism and regulatory force in schools, calling for the kind of talker who, in Baldwin (1963)'s words, "asks questions of the universe" and "examine[s] society," we will help teachers "change it and to fight it." Since the culture of a school influences the kind of talk that predominates (Cole 1997; Craig 2014) and how teachers talk influences the way in which teachers think about and act with children (Fennimore 2016), then changing daily talk is necessary to change practice.

\section{Constructing an Antiracist Ethos}

Ethicists find that quotidian actions, including words, determine and shape our conduct and values and vice versa (Dewey 2007; Foucault 1997; Lugones 2003; Morton 2019). María Lugones (2003) writes, "structures construct or constitute persons not just in the sense of giving them a façade, but also in the sense of giving them emotions, beliefs, norms, desires, and intentions that are their own" (60). Within this habitus, to use Pierre Bourdeau's (2008) phrase, we find a mutually reinforcing feedback loop between actions and values that is so internalized that the values that undergird one's actions are often rendered invisible. Bree Picower (2021) writes "teachers teach what they believe about how the world works, and what they believe has been influenced by broader societal forces that serve to justify current social orders" (6). In fact, much of what the teacher believes is not consciously understood but instead socially derived, so deeply entrenched in one's daily habitus that it is, as indicated in Jervis's (1996) story, rendered invisible to many (Love 2019; Picower 2021; Kendi 2019). Acting well is an arduous challenge when detrimental norms are reinforced by our daily surroundings (Foucault 1997; Kendi 2019; Menakem 2018).

To change this habitus requires an interruption in the chain of perception and/or action (Foucault 1997; Menakem 2018). Namely, one must practice what Michel Foucault (1997) refers to as a care of the self: regular, intentional engagement in exercises with an eye towards both conduct and philosophy. Using the metaphor of the athlete practicing just a "few moves," Foucault argues that key to care of the self is that the practices are limited, can be extended across a broad range of situations, and that these exercises are done separately from regular life (99). As Resmaa Menakem (2017) emphasizes, one needs to practice certain exercises, namely meditations, apart from antiracist work to prepare the groundwork for doing these exercises in the midst of antiracist work. Menakem writes:

Don't skip or skim the healing and grounding exercises in this book--the ones with activities that help you remember your body or perform an action. When you reach 
each one, stop. Take a few slow breaths. Then, as you read that section, practice that activity in your body. If you're not in a situation where this is possible, put the book down temporarily. Pick it up again when you have the opportunity to practice the activity. (30-31)

In other words, antiracist work requires a whole system of exercises that mutually reinforce each other--some of which are not explicitly related to combating racism. Further, where care of the self can be done individually, it is far more effective, influential, and sustainable as a collaborative venture (Foucault 1997; Menakem 2017).

A number of antiracist pedagogical exercises have been developed to change both how people see and act (DiAngelo 2018; Menakem 2018; Saad 2020; Taylor 2018). These exercises include having White people spend more time in situations and among peers where they are the racial minority (DiAngelo 2018); pursuing a meditative practice around one's racialized body (Menakem 2017); reflecting on labels, words, and language use that subtly reinforce racist attitudes (Taylor 2019); and engaging in antiracist "communication that fosters global change" (Ibid. 20). Truth-telling, a commitment to forthright and brave speech is one such exercise suited to disrupting habitus (Foucault 2001; 2012), and it is regularly called upon as a key player in antiracist work (DiAngelo 2018; Saad 2020; Taylor 2018; Tatum 2017).

As Beverly Tatum (2017) writes:

We need to continually break the silence about racism when we can. We need to talk about it at home, at school, in our houses of worship, in our workplaces, in our community groups. But talk does not mean idle chatter. It means meaningful, productive dialogue to raise consciousness and lead to effective action and social change. But how do we start? This is the question my students ask me. "How do I engage in meaningful dialogue about racial issues? How do I get past my fear? How do I get past my anger? Am I willing to take the risk of speaking up? Can I trust that there will be others to listen and support me? Will it make a difference anyway? Is it worth the effort?" (193)

Changing talk to confront racism is both necessary and challenging. As such the question becomes not whether we ought to change talk but how we might do so. Given that norms, including racist norms, are so deeply entrenched and that people tend to act in accordance with predetermined codes, what facilitates change?

\section{Descriptive Inquiry to Undergird Antiracist Talk}

We turn to Descriptive Inquiry, a practice that helped Cara and her colleagues to challenge ingrained and problematic racist norms in the opening scene. The roots of this paper began as we finished a project on how Descriptive Inquiry supported practical wisdom in four schools (Furman 2018; 2019; Furman \& Traugh 2021). Data consisted of four semi-structured interviews co-conducted with urban principals of three public progressive elementary schools: Jane Andrias, Central Park East, ${ }^{1}$ Alison Hazut and Michelle Harring, the Earth School, Judith Katz, the Neighborhood School; the principals' own writing that included

\footnotetext{
1 The principals have opted to use their real names in this IRB approved study.
} 
the writing of another Earth School principal, Abbe Futterman, and high school principal, Rachel Seher, City-as-School; notes taken during reviews at these schools spanning from 2002-2007, and our personal accounts as teacher and staff developer respectively in these schools. We also included commentary of other teachers within these schools that provided additional feedback and a counterbalance to the principals' perspective. In this way our findings are situationally triangulated by the different entry points to this work.

As predicated by grounded theory an underlying theme emerged after years of coding the data (Hubbard \& Power 1993). Just as Kendi (2017; 2019) has argued that racism lurks everywhere, issues of racism and moments of antiracist action were a steady theme. Descriptive Inquiry helped staff facilitate conversations about race with families, develop language for speaking about skin color and confronting stereotypes, reflect upon the racism in one's own practice and curriculum in order to make change, build and rebuild structures associated with special education so that fewer children of color were identified as needing services, and refocus teachers on a holistic and capacity oriented vision of the child to better support and advocate for particular children, a practice which disproportionately affected children of color (Furman \& Traugh 2021).

Maggie MacLure (2013) writes of data that glows: jumping out at the researcher and begging attention even when it doesn't conform with the pre-established codes. Such data provokes wonder and has the power to move the researcher to radically new spaces. Such a glow occurred when Cecelia commented amidst an interview:

When people find out that I've done a lot of work in exploring race using Descriptive Inquiry, people are interested in doing that. They're not interested in having me, this old white lady, for God's sake, come and talk about race. But they know I have a vehicle that's reasonably effective to safely raise some issues that are important and that relate to the persons in the immediate group, not the theoretical reading stuff.

(Furman \& Traugh 2021, 150)

That Descriptive Inquiry served as a vehicle that helped the schools challenge racism both directly and indirectly was manifestly clear (Furman \& Traugh 2021). What glowed and left us wondering was what made Descriptive Inquiry such an effective vehicle for addressing racism in these schools? For the remainder of this section, we look at how features of Descriptive Inquiry supported the cultivation of an antiracist ethos by influencing teacher talk.

Descriptive inquiry is a mode of inquiring about students, student work, and teaching centered on collaborative, phenomenological inquiry, and rooted in a generous and positive commitment to human capacity. As Judith explains, "the descriptive work is a vehicle for knowing and understanding children and understanding practice, too."

A defining and unusual feature of Descriptive Inquiry is that it both provides a clear structure for how one participates while the content under investigation and questions asked are very open. Before presenting, a participant meets with a "chair," a role Cecelia often played, to phrase a question that will be welcoming and expansive and to make sure, whenever writing about a child and a practice, that the writing is descriptive and informed by care. With the chair, the presenter also determines the mode of inquiry, namely, which process (described below) will be called upon and what content will be investigated. 
During an inquiry participants sit in a circle and speak in the order in which they are sitting, referred to as rounds.

The effect of rounds can be equalizing, bringing disparate perspectives into shared endeavor. In Judith 's words:

It helps people see themselves as part of a team that's working with the child. It's not only the classroom teacher and the specialists that are over there doing their own thing disconnected, but when people were doing a review, the teacher the year before might say something, the phys ed teacher, the librarian, the Spanish teacher, all would have a little piece of it too, a chance to say something. I think that's an important thing because usually those people are out in left field and the paraprofessionals often would say something. It also elevated the paraprofessionals, I think [by welcoming them as equals into the group when practices in many schools exclude them].

As participants share, the chair repeatedly pulls together themes that have emerged--helping everyone to come to shared meaning from their individual standpoints. ${ }^{2}$

A brief overview of each process as it was applied to antiracist work is as follows:

Reflection on a Word: Intended to unpack meaning behind a word and challenge preconceived notions, the chair and presenter identify a word that has proven important for a group. Participants are given a few minutes to write down all their associations with this word. Reflections often include etymology, different forms, synonyms, definitions, and popular usage. After everyone speaks, the chair pulls themes. For example, in a study of special education embarked upon with concern for the over diagnosis of children of color, Jane's staff reflected upon the word "special" and, in doing so, came to see the way that the world held positive connotations often omitted from "special education." This impelled teachers to think about "specialness" not as a negative euphemism for difference but as something unique to sustain and celebrate (Furman \& Traugh 2021, 99-100).

Anecdotal Recollection: Participants are given a prompt and asked to prepare a story to be shared (usually about 7 minutes in length). With an emphasis on what these stories might reveal about a topic as opposed to confession, participants share stories in rounds and then the chair pulls themes from across the stories. Judith shares a recollection that proved pivotal in her school's understanding of inclusion:

We [the whole staff] talked about when we were children in school, when did we feel known, when did we feel misunderstood or not liked, and when did school align with our particular interests. Questions like that. And it was very powerful what came out of it for people and people felt kind of released to be able to talk about that, and then what does that mean in terms of building our school. I think using that very particular personal experience does something for our children.

Review of Work: Participants choose a piece of written or visual work. The work can be created by anyone including, a child, teacher, professional artist, or professional writer. With images, participants describe in depth with phrases like, "a circle on top of a figure," with an emphasis on avoiding inferences like, "there's the head." With written work, participants often first choose a passage and share why they chose it. They then conduct a descriptive study of an extended passage (typically about 250 words) in which participants move from reading the passage out loud, word for word paraphrasing, and then providing

\footnotetext{
2 This process is akin in spirit of Paulo Freire's (2000) culture circles though unlike Freire's work, Descriptive Inquiry provides a more concrete set of practices to facilitate enactment.
} 
descriptive commentary. Cecelia and Abbe did a review of the Baldwin quote at the start of this essay within a parent group developed to "consider the challenges and rewards of being a parent in a diverse community" (Furman \& Traugh 2021, 183). The review of this passage served as a launching point to consider "the implications of his [Baldwin's] ideas for the school's mission" which was also read closely through the review of work (184).

Review of the Child: A teacher describes a child they puzzle over through a capacious lens guided by the headings: physical presence and gesture; disposition and temperament; connections with others, strong interests and preferences; modes of thinking and learning. In describing the child in depth and hearing her colleagues' feedback, Cara always gained insights into a child's way of knowing. As occurred in the opening anecdote, presenting the child to the staff served as a form of advocacy as children often rendered invisible and/or hypervisible were seen more holistically and capaciously.

Review of Practice: A practitioner surfaces a question about their work complemented by an in-depth narrative description of practice. Colleagues describe what they've heard and then respond to the presenter's focus questions. As a classroom teacher, Alison presented the query, "How do I create an environment respectful of race? How do we do the same within the school? How can we as a school staff find a way to talk about issues of race and diversity that will be helpful to us?" alongside a detailed description of the changing ways she addressed race in the classroom.

Reinforcing that everyone has knowledge to share, an inquiry often ends with participants offering ideas to bring back to practice phrased as, "you might try" never as "you should." These include activities, questions, things to perhaps look for (such as how a child is different at recess). The presenter does not respond directly and participants are left to decide how they will bring ideas from the review forward.

Emphasizing its integral role in the school, Alison repeatedly used the phrase "woven in" to describe how Descriptive Inquiry lived in every part of school life. Alison explains:

DI [Descriptive Inquiry] was woven into all aspects of school life: we had a descriptive stance when looking closely at our work through the lens of PD [professional development] but also in terms of how we saw children, their strengths and needs. DI was used to plan for a wide range of meetings and workshops with parents. In its most formal sense, DI was practiced through reviews of children, their work, teacher's practice--we did a review of our school through the study of our archive work on DI and the issues the school was grappling with over time.

Jane added that individual inquiries tended to be part of year-long investigations into topics such as special education, play, literacy, or math. Within these year-long studies there was also space for unexpected inquiries. Each school described using the processes to figure out how to respond to crises such as 9/11, natural disasters, and Covid-19.

Sonya Renee Taylor (2019) provides 14 criteria that supports "communication that grows our understanding of ourselves and one another--the type of communication that fosters global change." These include "engage and encounter curiosity-driven dialogue, not debate or arguing," "embrace multiple perspectives," "practice unapologetic inquiry," "have a conversation based on what was actually said," "assume the best about one another," and "celebrate difference" (95-97). In considering these criteria alongside other antiracist literature, we boil Taylor's criteria into three main qualities required for antiracist communication: the capacity to sustain difficult conversations, work towards a positive and capacious view of the individual, and a commitment to on-going inquiry in the service of growth. Descriptive Inquiry meets these criteria. 


\section{Difficult Conversations}

A key factor in the Jervis (1996) account was the inability of teachers to speak meaningfully and openly together. Truth-telling requires bravery--often requiring one to engage in conversations that feel, and sometimes are, risky (Foucault 2001). For Black participants, conversations about race can be painful and place one in a vulnerable, even dangerous position (Dillard 2012; Menakem 2017; Saad 2020; Tatum 2017). White participants frequently get defensive, shut down, avoid the topic, and lash out (DiAngelo 2018; Love 2019; Menakem 2017; Tatum 2017). Antiracist work is supported when participants are challenged within an environment in which trust has been sought (Kendi 2019; Menakem 2017; Picower 2021).

Each principal argued that Descriptive Inquiry provided spaces for teachers to come together and speak openly and shared how Descriptive Inquiry facilitated difficult conversations ranging from talk about race and racism, how to support a particular child a teacher was frustrated with, determining how to respond to 9/11, talking openly with parents about how a child is doing in school, and supporting a struggling colleague.

Jane described how the capacity to speak openly with colleagues was especially difficult and needed when there were concerns about someone's work with children:

In some cases [when a teacher was struggling], we would consider a Review of Practice so that would be helpful to them. But nobody balked at framing something as an issue, even an interpersonal issue, through Descriptive Inquiry. Nobody balked at it. ... When I had a very serious problem with a teacher, who was very very angry with me and we were not moving anywhere, I asked her to select a couple of people she trusted in the school and then we opened it to a few more people and then we had a small advisory group and somebody ran it. If I was the issue, then I didn't [run it]. ... It seemed that the formal process [of Descriptive Inquiry] became a safe way for people to say what was on their mind and then to come to new understandings about it. When in the course of our daily lives in school, did we always act from that place?

No, but we could go back to it.

Striking in this description is the space for "trust" and "safety." Working with a teacher who was angry at her, the principal, Jane, drew on the processes and encouraged the teacher to reach out to those she trusted. Descriptive Inquiry then provided a structure that facilitated difficult conversations.

In the previous passage Jane both captures how the processes enabled particular conversations and, through regular exercise, created a foundation to "go back to" in "our daily lives." The other principals also credited Descriptive Inquiry with both supporting individual conversations and laying the groundwork for dialogue. In fact, all but one of the principals took over their school amidst much turmoil. As captured by Judith, "I was all excited and ready to start, teachers were all completely wrecked and fighting, and I thought oh my God, this is gonna be really bad." Each turned to Cecelia to "run these meetings," bringing the Descriptive Processes to the schools (see Furman \& Traugh Chapter 4 for a detailed discussion of this process in Rachel's school). They credited Descriptive Inquiry with, in the words of Michelle, serving as "an amazing unifying factor for that difficult year."

What made Descriptive Inquiry so effective at facilitating a culture capable of difficult conversation? Speaking in rounds, people know how much time they will get to speak and when their turn will come. As Judith commented, "they're not free for alls; everybody gets a turn." This structured turn-taking alleviated some common hindrances to safe 
conversation. Namely, people speaking over each other, interrupting, dominating the conversation, or not entering it at all. For "some" teachers, as Jane says, this change in speech patterns "was just a challenge for them... a challenge to wait their turn or be part of the process, and not sit above it or outside of it or be the authority on it." That said, Judith describes how the processes drew teachers into more productive sharing:

We had a teacher who always said really pithy things [informally], but [in regular meetings] she would never talk in a group, but [during Descriptive Inquiry] she also wouldn't say, 'I pass.' So she would participate under the circumstances...

The ritualized habit of speaking and listening provided people in the schools, in Michelle's words, "a basis for how to talk to each other." As Alison commented, "because we used DI, our formal PD and other kinds of meetings with parents, in committees and such were always grounded in processes that allowed and expected everyone to share and listen to one another." This led to improved communication outside of the official practice of Descriptive Inquiry.

The charge to speak descriptively, attend with care, and offer ideas to think with as opposed to suggestions also structured people's participation and helped teachers and principals say what they considered to be difficult things. In fact, regular practice of Descriptive Inquiry changed how people spoke. Judith describes a teacher who often would "pout if she didn't like what was going on" but "felt herself on her best behavior" during Descriptive Inquiry sessions. Judith found from regular practice of Descriptive Inquiry she herself became skilled at speaking descriptively and because of this, "I've also said some hard things to parents that they have accepted and teachers have said hard things and they say 'well you know my child. You really know that child, so I'm hearing what you say.'”

The ability to grow and share has been linked to one's capacity to be vulnerable (Brown 2015). Yet, vulnerability demands a community in which one trusts they will be respected. We learn to be vulnerable when others, especially leaders, model this through brave sharing. Judith comments,

I think one of the important things about descriptive work, too, is if you look at teachers as being very isolated, this has teachers being not isolated. And it breaks down those barriers, and it also lets teachers be comfortable in front of each other, and be open and honest, and not have to hide.

An environment in which teachers felt connected and comfortable, in other words, allowed for "open and honest" speech.

Similarly, describing the vulnerable sharing of practice enabled by Descriptive Inquiry, Michelle commented,

The teachers did Reviews of their work, I did Reviews of my work as a school leader, and so there was a lot of laying it out there for people (laughs). There was a lot of opening it up and allowing yourself to be vulnerable, and I think that was ... one of the functions that Descriptive Review does for teachers.

Speaking of the modeling that occurred as new teachers entered into this process, Michelle explains that through all this sharing, a school culture developed in which teachers "would get to know fairly intimately the thoughts and ideas of other teachers and get to know these other teachers."

This regular exercise of sharing oneself made space for important and sensitive truths to be expressed. As noted previously, when Judith's colleagues used the anecdotal recollection to share times when they felt included and excluded, "people felt kind of released to be 
able to talk about that." The conversation ultimately paved the way for more open discussion of exclusion and shifted practice to better care for children.

\section{Positive and Capacious View of the Individual}

Being antiracist, according to Kendi (2019) "is ultimately about the basic struggle we're all in, the struggle to be fully human and to see that others are fully human" (11), a commitment that ought to carry over and be supported in schools (Jones \& Hagopian 2020). Yet recognizing a student's full humanity and capacity is, as documented by Richard Milner (2010), very difficult when that student is regularly "overlooked and undervalued," omissions which commonly occur when someone has been "known" "only in a negative light" (184). This "overlooking and undervaluing" of Black children manifests with alarming frequency as stereotypes, hypervisibility (often with negative assumptions) and invisibility (either not noticing a child at all or noticing only superficially and not seeing the child in their rich particularity) (Ferguson 2001; Ife 2017; Lomboy et al. 2020; Love 2019; Richards et al. 2019, Walker et al. 2017). Further, where the capacity to know someone is never fully possible, this gulf is often exacerbated when people come from different racial and cultural groups (Lugones 2003; Siddle Walker \& Snarey 2004).

Love (2019) writes:

Black folx are highly visible and invisible at the same time. The sad truth is that White people can spend their entire lives ignoring, dismissing, and forgetting dark peoples' existence and still be successful in life. The latter is not the same for us. (127)

With a majority of White teachers serving Black children (Picower 2021), Black children depend upon the care of unseeing adults. This is compounded by the fact that within a racist society teachers of color, including Black teachers, also often hold detrimental and limited views of Black children (Kendi 2018; Milner 2010).

To combat racism, teachers need regular exercise in seeing children more capaciously (Love 2019; Milner 2010; Souto-Manning \& Martell 2016). The words one uses can influence what someone does and doesn't see. In guiding and shifting a person's language, Descriptive Inquiry can serve as a vehicle for seeing the person both holistically and through a capacity-oriented lens (Ascenzi-Moreno et al. 2008; Furman \& Traugh 2021; Gasoi et al. 2016; Himley et al. 2000). Speaking to the constant need for staff development on this front Michelle commented, "we tended to have new teachers with little experience and not necessarily a whole lot of language to talk about children and to talk about their own practice or about curriculum." Descriptive Inquiry helped teachers dually see children more fully and see past preconceived notions by guiding the kind of talk allowed. Again, in Michelle's words:

There are rules in Descriptive Review and one of the most important rules has got to do with not allowing for any labeling and not allowing for any mixing up the difference between what you see with making judgements about it. And so the judgement part of it was something that actually for many people slows them down. The observational part slows them down, and not being able to make judgements about it for awhile also slows them down because once you make a judgement there's closure, and you just don't want that to happen, so the slowing down of that process was interesting. 
Slowing down to describe, in Judith's words,

teaches [us] to look more deeply at children's work. I think you [referring to Cecelia] said that you felt at the beginning [of bringing Descriptive Inquiry to the school] that teachers were thinking superficially and I think that the use of descriptive work kind of forces or pushes teachers to think more deeply.

Michelle summarizes the effect saying this

in depth looking at what a child does and all of the facets, from handwriting to the gesture, to how much writing or what he was writing about or how she was drawing. It gave teachers an opportunity to see children in a much deeper way.

Striking is the repetition of words that connote depth and the way that the processes helped people to speak differently and, in doing so, see what they had previously not noticed.

In addition to supporting capacious description, Descriptive Inquiry opened a space for various teachers and even parents to come together in meaningful talk in order to find ways to sustain a child. Capturing this process, Jane explains,

When we had a child that presented us with questions that we did not know how to answer, we always gathered the people who worked with the child from the beginning. Usually our kids started very young and somebody would meet with the parents to get a fuller picture and that was sort of done in an organic way but it became much more formal after awhile. ... People always depended upon others to help them know the child. The descriptive work certainly helped with that. You can't escape that when you're involved in a Descriptive Review. There was a sort of mutuality with the process of knowing a child in every possible way as fully as possible.

Through gathering to speak positively in a community of concerned adults with the child's interest at the center, Descriptive Inquiry was used to reclaim and reshape individual teachers' perspectives on the children in their care and cultivated a school ethos in which such a perspective became the expectation. The practice of speaking about students as complex and capable in Descriptive Inquiry led to a change in how people oriented themselves on a daily basis. As Jane commented,

the ethic of really knowing the child is really really strong in the school. We tried to do two [reviews of children] a month and descriptions of work we did more frequently. But what was more important was holding the stance.

In guiding language to be descriptive and positive, Descriptive Inquiry both helped teachers know children better and commit to "holding a stance" that valued this kind of knowing. Nevertheless it is important to note that these conversations about children could still be very difficult, even fraught, as they were in the opening anecdote for Cara and her colleagues. Using Descriptive Inquiry to change the way special education was approached in the school, Jane comments, "It was very hard because people began to realize that they were using language that was very detrimental."

Finally, the racial implications were significant. Over the course of a given year, the majority of students described in Reviews at Cara's school were children who identified as Black or Latinx. As Love notes at the opening of this section, the stakes are very high for a Black child who must endure a classroom where their teacher finds them mysterious. Descriptive Inquiry helped lessen the mystery, making the child more fully known and better attended to with care. This had very tangible implications. As described in the opening 
anecdote, the processes helped Cara and her colleagues speak capaciously to combat the overdiagnosis of Black children as having special needs (Furman \& Traugh 2021).

\section{On-Going Inquiry in the Service of Growth}

Because racism is so deeply rooted and pervasive, challenging it demands on-going and regular inquiry into one's beliefs and practices (DiAngelo 2018; Kendi 2019; Picower 2021). Capturing the constant nature of the struggle, Picower (2021) writes:

As a White person doing this work, there is never a point of "arrival," and I continue to reflect on my racial identity, navigating certain tensions and setting intentions. Part of the process of moving toward anti-racism is constant self-examination and a questioning of what work I should or should not be doing given my positionality as someone who ultimately benefits from the system of racism. I also notice this questioning of self as a pattern with the White teachers I work with as they begin the journey of becoming more racially conscious (e.g., "How can I teach about race as a White person with all Black students?"). I've come to believe this self-consciousness is a part of the process of trying to be a responsible White person in racial justice work. (15-16)

Similarly, Kendi (2018) identifies his struggles as a Black man:

I used to be racist most of the time. I am changing. I am no longer identifying with racists by claiming to be "not racist." I am no longer speaking through the mask of race neutrality. I am no longer manipulated by racist ideas to see racial groups as problems. I no longer believe a Black person cannot be racist. I am no longer policing my every action around an imagined White or Black judge, trying to convince White people of my equal humanity, trying to convince Black people I am representing the race well. I no longer care about how the actions of other Black individuals reflect upon me, since none of us are race representatives, nor is any individual responsible for someone else's racist ideas. And I've come to see that the movement from racist to antiracist is always ongoing--it requires understanding and snubbing racism based on biology, ethnicity, culture, behavior, color, space, and class. (10)

Both Picower and Kendi insist upon a constant commitment to inquire into one's beliefs and adapt them in the service of antiracist thinking and action. The commitment to inquiry necessary for antiracist work was cultivated through regular practice of Descriptive Inquiry. Teachers brought questions to the monthly reviews. Framing the reviews around their own questions kept talk, and the thinking that followed, open to possibility. As ideas not suggestions were offered, teachers both had practical actions to try while keeping the space for uncertainty open.

This commitment to inquiry lived in the schools outside of Descriptive Inquiry sessions. Alison explains:

Teachers also had an area of focus or an essential question that was on their minds-we would discuss this together in connection to observation and feedback sessions (not only with me, but through Peer Mentorship we did this for several years--teachers were matched/self selected with others who they could observe and spend time 
together debriefing without me around $(;)$ and these areas of focus/questions of prac-

tice were also explored through grade team work and whole staff PD.

In other words, as Alison describes, "A stance [was developed] among the teachers that they didn't have all the answers, that the questions were as important." Inquiry permeated the daily life of the school and was sustained through regular practice.

One subtle space where vigilant inquiry is needed is in everyday language. Explaining the word "racist," Kendi (2019) writes, "it is descriptive, and the only way to undo racism is to consistently identify and describe it-- and then dismantle it" (9). Similarly, describing a hairstyle as "locks" Cynthia B. Dillard (2012) comments, "how could anything so beautiful, so absolutely splendid even begin with the word 'dread?"” and continues:

Naming creates identity: It matters deeply how I refer to my Self and how I refer to my hair and other things I care about, as the language we use tells a deeper truth about our lives and our relationship to life. (36)

Exact language is significant and improved language requires inquiring into the meaning of words and then reshaping them.

As Kendi and Dillard argue we must do, Descriptive Inquiry guides participants to attend to minute but crucial details. As previously described, a child's drawing is reviewed with care taken to avoid inferences.

Reflecting on a word, teachers unpack and expand on regularly used language. As Jane comments:

What really began to change was the way we talked about children . . . with the idea that if somebody is saying that a kid is "lazy" then someone else can say, "well what do you mean by that? What does that word mean?" ... We certainly help the person give examples and describe what he or she was witnessing or experiencing. . . Many people began to take more responsibility for questioning people for the language they were using. That certainly happened in the formal meeting but it was happening more and more in the casual conversation that people had.

Just as Dillard needed to remove "dread" from locks, teachers needed to address the casual way in which they described the action of not producing something as "lazy," the moving child as "distracted," or a child regularly touching peers as "aggressive." In describing, one keeps one's gaze ever fresh--pushing past assumptions to maintain a stance of constant inquiry in the pursuit of more just ways of seeing and being.

Finally, in the Descriptive Review, the describer recognizes the child as another person and in this recognition acknowledges that they as describer offer an interpretation not a complete rendering of the person described. The describer certainly learns about the described, whether it be a child, a piece of children's work, or a teaching practice, but very importantly, the describer learns about themself--their assumptions, habituated ways of seeing and responding, and language. Assuming shared humanity but setting aside assumptions of cultural sameness is critical for knowing the child as a person and for antiracist work.

\section{Descriptive Inquiry and Antiracist Pedagogy}

Antiracist work within a racist society is both necessary and arduous. As noted in the opening anecdotes and subsequent analysis, the capacity to engage in antiracist conversation productively can be both hindered and supported by the immediate environment in which 
the speakers are operating. Menakem (2017) urges that for participants to fully do the antiracist work he describes, they ought not pick and choose exercises from his book, but take the time to work through all of them with care. In other words, to prepare for the challenge of antiracist work one needs practices that prepare one both for the habits of mind needed to do this work and a mechanism to facilitate the work itself.

In Descriptive Inquiry each exercise has value in and of itself but also, when combined, prepares the teacher for the capacity to engage in antiracist conversation. Further, while there are many useful protocols for having meaningful discourse, three elements of Descriptive Inquiry particularly lend themselves to antiracist work. Namely, the facilitation of difficult conversations, cultivation and maintenance of a positive and capacious view of the individual, and engagement in on-going inquiry.

Ultimately, these qualities supported teachers coming together to have conversations about race and racism. Specifically describing talk about race with families, Judith speculates:

I don't think we would have gotten to that place or been able to really work in that honest and raw way if we didn't have the experience of teachers and parents together looking at questions and parents said the work we did on Saturdays or after school was so important--that work was so important to them.

That said, it is important to emphasize that Descriptive Inquiry is not, in the words of Michelle, "a panacea." As we have highlighted elsewhere, there were times where individual teachers and schools struggled with difficult conversations, a positive and capacious approach, and upholding space for inquiry even as they practiced Descriptive Inquiry with regularity (Furman \& Traugh 2021).

Descriptive Inquiry is not synonymous with antiracist work. In fact, racism can and does occur among people who practice Descriptive Inquiry. This is highlighted in Jervis' (1996) account in which Descriptive Inquiry was practiced but not, in the school's inception, applied to issues of race. Though Cara benefited from being in a school where she could draw on Descriptive Inquiry and the habits of mind cultivated to challenge racism, the opening anecdote acknowledges the presence of racism was still there and the conversations were always difficult, demanding careful preparation, and including anger and pain. These schools had to also proactively and directly address race and racism (Furman \& Traugh 2021). The processes facilitated content combatting racism but they did not replace it. Finally, the processes themselves are imperfect--developed within a society that is racist. In fact, within the community that practices Descriptive Inquiry, there has been on-going work and revision to change and grow the processes in conjunction with antiracist work.

As such, we close with the humble claim. If we are to have the necessary capacities available in discussions about race we must practice these ways of talking and seeing regularly and over time and, include exercising these capacities in both similarly high stakes settings as well as lower stakes situations. In other words, we must practice the needed abilities to challenge racism within and outside of conversations about race and racism. Finally, we must not settle into complacency---assuming that because we are doing some good work (such as Descriptive Inquiry) we are automatically immune to racism or above it. Gratitude to those in the Philosophy Fellowship and the Humanistic Approach to Child Study group for thinking with us. Instead, we must build schools that encourage individuals "To ask questions of the universe, and then learn to live with those questions," "to examine society and try to change it and to fight it - at no matter what risk" (Baldwin, 1963). We describe how Descriptive Inquiry helped four schools do this work and, at the time of publication, the work remains unfinished. 
Acknowledgements This research was supported by a grant from the Cottonwood Foundation.

\section{References}

Alexander, Michelle. 2012. The New Jim Crow: Mass Incarceration in the Age of Colorblindness. Revised. New York: New Press.

Ascenzi-Moreno, L., C. M. Espinosa, S. Ferholt, M. Loeb, B. Lugo-Salcedo, and C. Traugh. 2008. Profiles and perspectives: learning through descriptive inquiry at the cypress hills community school. Language Arts 85 (5): 392-400.

Baines, Janice, Carmen Tisdale, and Susi Long. 2018. We've Been Doing It Your Way Long Enough: Choosing the Culturally Relevant Classroom. Language and Literacy Series. New York, London: Teachers College Press.

Baldwin, James. 1963. A Talk to Teachers. Saturday Review. https://www.spps.org/cms/lib010/MN019 10242/Centricity/Domain/125/baldwin_atalktoteachers_1_2.pd.

Bourdieu, Pierre. 2008. The Logic of Practice. Reprinted. Stanford, Calif: Stanford Univ. Press

Boutte, Gloria, and Nathaniel Bryan. 2019. When will black children be well? Interrupting anit-black violence in early childhood classrooms and schools. Contemporary Issues in Early Childhood unassigned. 1-12.

Brown, Brené. Daring Greatly: How the Courage to Be Vulnerable Transforms the Way We Live, Love, Parent, and Lead, 2015. http://jeffco.axis360.baker-taylor.com/Title?itemid=0010971012.

Coates, Ta-Nehisi. 2017. We Were Eight Years in Power: An American Tragedy, First edition. New York: One World.

Cole, Ardra L. 1997. Impediments to reflective practice: toward a new Agenda for research on teaching. Teachers and Teaching: Theory and Practice 3 (1): 7-27.

Connor, David J. 2017. Who is responsible for the racialized practices evident within (special) education and what can be done to change them. Theory into Practice 56 (3): 226-233.

Craig, Cheryl J. 2014. From stories of staying to stories of leaving: a US beginning teacher's experience. Journal of Curriculum Studies 46 (1): 81-115.

Dewey, John. 2007. Human Nature and Conduct an Introduction to Social Psychology. New York: Cosimo.

DiAngelo, Robin J. 2018. White Fragility: Why It's so Hard for White People to Talk about Racism. Boston: Beacon Press.

Dillard, Cynthia B. 2012 Learning to (Re)Member the Things We've Learned to Forget: Endarkened Feminisms, Spirituality, \& the Sacred Nature of (Re)Search \& Teaching. Black Studies \& Critical Thinking, v. 18. New York: Peter Lang

Emily, Gasoi, Abby Hare, Norah Malloney, and Hanna-Stevens. Morin. 2016. Professional development of by, and for the practitioners of the washington teachers inquiry group. Schools Studies in Education. 13 (2): 273-293.

Fennimore, Beatrice S. 2016. Say that the river turns: social justice intentions in progressive public school classrooms. Occasional Papers Series 35: 61-74.

Fennimore, Beatrice S. 1997. The Essential Works of Michel Foucault, 1954-1984. Translated by Paul Rabinow and James D Faubion. New York: New Press.

Ferguson, Ann Arnett. 2001. Bad Boys: Public Schools in the Making of Black Masculinity. 1st pbk. ed. Law, Meaning, and Violence. Ann Arbor: University of Michigan Press.

Foucault, Michel. 2001. Fearless Speech. Translated by Joseph Pearson. Los Angeles, Ca[lif.]: Semiotext(e): [Distributed by MIT Press]

Frank, Jeff. 2018. Teaching is oppositional: on the importance of supporting experimental teaching during student teaching. Studies in Philosophy and Education 37 (5): 499-512.

Frank, Toya Jones, Marvin G. Powell, Jenice L. View, Christina Lee, Jay A. Bradley, and Asia Williams. 2021. Exploring racialized factors to understand why black mathematics teachers consider leaving the profession. Educational Researcher. https://doi.org/10.3102/0013189X21994498.

Freire, Paulo. 2018 Pedagogy of the Oppressed. 30th anniversary ed. New York: Continuum, 2000.

Furman, Cara. 2018. Descriptive inquiry: cultivating practical wisdom with teachers. Teachers and Teaching: Theory and Practice 24 (5): 559-7.

Furman, Cara E. 2019. Descriptive inquiry: care of the principal self. Ethics and Education 14 (3): 298315. https://doi.org/10.1080/17449642.2019.1617390.

Furman, Cara E., and Cecelia Traugh. 2021. Descriptive Inquiry in Teacher Practice: Cultivating Practical Wisdom to Create Democratic Schools. New York: Teachers College Press.

Glaude, Eddie S. 2008. In a Shade of Blue: Pragmatism and the Politics of Black America. Chicago [Ill.]; London: University of Chicago Press.

Hartman, Saidiya V. 1997 Scenes of Subjection: Terror, Slavery, and Self-Making in Nineteenth-Century America. Race and American Culture. New York: Oxford University Press 
Himley, Margaret, and Patricia F. Carini, eds. 2000. From Another Angle: Children'S Strengths and School Standards: The Prospect Center'S Descriptive Review of The Child. New York: Practitioner Inquiry Teachers College Press.

Hubbard, Ruth Shagoury, Brenda Miller Power. 1993. The Art of Classroom Inquiry: A Handbook for Teacher-Researchers. Portsmouth, N.H: Heinemann

Ife, Fahima I. 2017. Perhaps a black girl rolls her eyes because it's one way she attempts to shift calcified pain throughout her body. Occasional Papers Series. 2017 (38): 29-35.

Jervis, Kathe. 1996. "How come there are no brothers on that list?": hearing the hard questions all children ask. Harvard Educational Review 66 (3): 546-577.

Jones, Denisha, and Jesse Hagopian, 2020. eds. Black Lives Matter at School: An Uprising for Educational Justice. Chicago, Illinois: Haymarket Books.

Kendi, Ibram X. 2017. Stamped from the Beginning the Definitive History of Racist Ideas in America. New York, N.Y: Bold Type Books.

Kendi, Ibram X. 2019. How to Be an Antiracist, 1st ed. New York: One World.

Lamboy, Lily, Ashley Taylor, and Winston Thompson. 2020. Paternalistic aims and (mis)attributions of agency: what the over-punishment of black girls in us classrooms teaches us about just school discipline. Theory and Research in Education. 18 (1): 59-77.

Leafgren, Sheri. 2018. The disobedient professional: applying a nomadic imagination toward radical noncompliance. Contemporary Issues in Early Childhood Education 19 (2): 187-198.

Love, Bettina L. 2019. We Want to Do More than Survive: Abolitionist Teaching and The Pursuit of Educational Freedom. Boston: Beacon Press.

Lugones, Maria. 2003. Pilgrimages =: Peregrinajes: Theorizing Coalition against Multiple Oppressions. Feminist Constructions. Lanham, Md: Rowman \& Littlefield

MacLure, Maggie. 2013. The wonder of data. Cultural Studies $\leftrightarrow$ Critical Methodologies 13(4):228-32 https://doi.org/10.1177/1532708613487863

McGhee, Heather C. 2021. The Sum of us: What Racism Costs Everyone and How We Can Prosper Together First Edition. New York: One World.

Menakem, Resmaa. 2017. My Grandmother'S Hands: Racialized Trauma and The Pathway to Mending Our Hearts and Bodies. Las Vegas: Central Recovery Press.

Milner, H. Richard. 2010. Start Where You Are, but Don't Stay There: Understanding Diversity, Opportunity Gaps, and Teaching in Today's Classrooms. Cambridge, Mass: Harvard Education Press

Morton, Jennifer M. 2019. Moving up without Losing Your Way: The Ethical Costs of Upward Mobility. Princeton, New Jersey: Princeton University Press.

Moten, Fred. 2017. Black and Blur, Consent Not to Be a Single Being, v. [1]. Durham; London: Duke University Press.

Paris, Django, H. Samy Alim. 2017. eds. Culturally Sustaining Pedagogies: Teaching and Learning for Justice in a Changing World. Language and Literacy Series. New York: Teachers College Press

Picower, Bree. 2021. Reading, Writing, and Racism: Disrupting Whiteness in Teacher Education and in the Classroom. Boston: Beacon Press.

Richards, Jennifer Smith, Jodi S. Cohen, and Lakeidra Chavis. 2020. The Quiet Room. Chicago Tribune, 2019.

Saad, Layla F. 2020. Me and White Supremacy: Combat Racism, Change the World, and Become a Good Ancestor. Napreville, Illinois: Sourcebooks.

Santoro, Doris A. 2015. Philosophizing about teacher dissatisfaction: a multidisciplinary hermeneutic approach. Studies in Philosophy and Education 34 (2): 171-180.

Shalaby, Carla. 2017. Troublemakers: Lessons in Freedom From Young Children at School. New York: The New Press.

Souto-Manning, Mariana, Jessica Martell. 2016. Reading, Writing, and Talk: Inclusive Teaching Strategies for Diverse Learners, K-2. Language and Literacy Series: Teachers College Press. New York

Tatum, Beverly Daniel. 2017. "Why Are All the Black Kids Sitting Together in the Cafeteria?": And Other Conversations about Race. Third trade paperback edition. New York: Basic Books

Taylor, Sonya Renee. 2018. The Body Is Not an Apology: The Power of Radical Self-Love, First Edition. Oakland, CA: Berrett-Koehler Publishers.

Walker, Danielle, Chery E. Matias, and Robin Brandehoff. 2017. "Who you callin' smartmouth?" misunderstood traumatization of black and brown girls. Occasional Papers Series. 2017 (38): 43-47.

Walker, Vanessa Siddle, and John R. Snarey. 2004. eds. Race-Ing Moral Formation: African American Perspectives on Care and Justice: Teachers College Press. New York

Wilkerson, Isabel. 2020. Caste: The Origins of Our Discontents First Edition. New York: Random House.

Publisher's Note Springer Nature remains neutral with regard to jurisdictional claims in published maps and institutional affiliations. 